\title{
PROGRAMMED LEARNING IN MEDICAL EDUCATION
}

\author{
An Experimental Comparison of Programmed Instruction by Teaching Machine \\ with Conventional Lecturing in the Teaching of Electrocardiography \\ to Final Year Medical Students
}

\author{
S. G. OwEN, M.D., M.R.C.P. \\ Senior Lecturer in Medicine.
}

J. Anderson, M.B., M.R.C.P. Lecturer in Medicine.

\author{
R. HaLl, B.Sc., M.D., M.R.C.P. \\ Wellcome Senior Research Fellow in Clinical \\ Science and Honorary Lecturer in Medicine. \\ G. A. Smart, B.Sc., M.D., F.R.C.P. \\ Professor of Medicine.
}

Department of Medicine, University of Newcastle upon Tyne.

THOUGH programmed learning is an educational technique which is gaining increasing acceptance in other spheres, its possible usefulness in medical education largely remains to be evaluated. The purpose of this investigation was to determine the relative efficiency of a teaching-machine course in electrocardiography and a series of conventional lectures on the same subject. In planning the experiment we were guided by the criteria laid down by Cheris (1964) for valid comparisons of programmed and non-programmed instruction.

\section{The Programme}

Electrocardiography was chosen as a particularly appropriate subject for programming, being logical, self-contained and well adapted for visual presentation. The programme, development of which has already been described (Owen, Hall and Waller, 1964), was written by one of us (S.G.O.) for the purpose of this trial. It was "validated" (i.e. tested) on twelve final year medical students and subsequently revised. The final version* used in this experiment consists of 604 pages or "frames", 254 of which represent the main learning sequence and the remainder remedial material.

Presentation was by means of the Grundytutor teaching machine. Each student had his or her own machine, and four stand-by machines were also available in case of breakdowns. Students were allowed to use the machines whenever they wished and a technician was always available to deal with mechanical faults. Each student was provided

*Published in December, 1963, as "Principles of Electrocardiography" by S. G. Owen (International Tutor Machines Ltd., Ashford, Middlesex, England). with a note-book and log-sheet and was required to record the duration of each session spent at the machine.

\section{The Lectures}

The lectures, which were all given by one of us (R.H.), were prepared from the teaching programme and fulfilled the most important criterion of any comparative study-that of identical content. Concepts and examples were the same as those used in the programme and all diagrams and electrocardiograms in the? programme were reproduced as slides and projected during the lectures. Fourteen lectures were given, each of 50 minutes duration. This number was not fixed in advance, in order to allow the lecturer optimal coverage of the subject. An attendance register was kept, and students who missed a lecture had it repeated to them before the next session.

\section{The Subjects}

Seventy-seven medical students at the end of their fifth year of study volunteered to take part in the experiment. None had much knowledge of electrocardiography. Thirty-six students were allocated to teaching-machines (the number available) and the remaining forty-one to the lecture series, the two groups being matched on the basis of previous academic performance. Mean "academic ratings" (derived from the sum of scores in professional examinations) were identical (machine group 68.5 \pm SD 19.52; lecture group 68.5 \pm SD 20.59). There was no other basis of selection except in the case of six female students with prearranged resident midwifery appointments who were assigned to machines because of their inability to attend lectures. 


\section{Method of Assessment}

Teaching efficiency was assessed by means of a three-hour examination, which all students sat within a week of completing the course. This was designed to test understanding of electrocardiographic theory and practical ability in interpretation of electrocardiograms. Multiple choice questions were not used lest they should favour the machine group, who by then were familiar with the multiple choice technique. Eight hospital doctors accustomed to routine reporting on electrocardiograms sat the same examination independently in order to provide a reference standard. Test papers, identified only by a code number, were scored independently by two of us according to a previously agreed scale and the two sets of scores were compared. In one or two cases of discrepancy, the paper was re-scored jointly.

The final test scores proved to correlate highly with academic rating, confirming the validity of the matching procedure $(r+0.51$, $\mathrm{P}<.001)$. This correlation proved valuable in assessing interaction effects between teaching method and other classifications (e.g. sex, nationality), analysis of covariance being applied to eliminate sampling fluctuations in respect of initial ability between sub-groups.

At the end of the experiment, students in both groups were also asked to complete a questionnaire designed to assess their subjective reactions to the teaching methods.

\section{Results}

\section{Overall Comparison of Teaching Methods}

The distribution of final test scores is shown in Fig. 1. There was no significant difference in performance between the two groups of students. Both methods of teaching were effective, as shown by the comparability of the students' scores to those obtained by the eight hosnital officers with practical experience in ECG interpretation.

Nor did either method prove more efficient in terms of total learning time required (Table 1). The average time taken to complete the machine course (14.3 hours \pm SD 5.82) was appreciably longer than the time spent in lecturing to the control group (11.7 hours), but the latter spent significantly more time on additional work during the course - a not unexpected finding, since both the continuous accessibility of the teaching-machines and their built-in facility for self-paced revision would tend to reduce the amount of work done away from them. It should be noted, however, that the lecture group also spent more time on

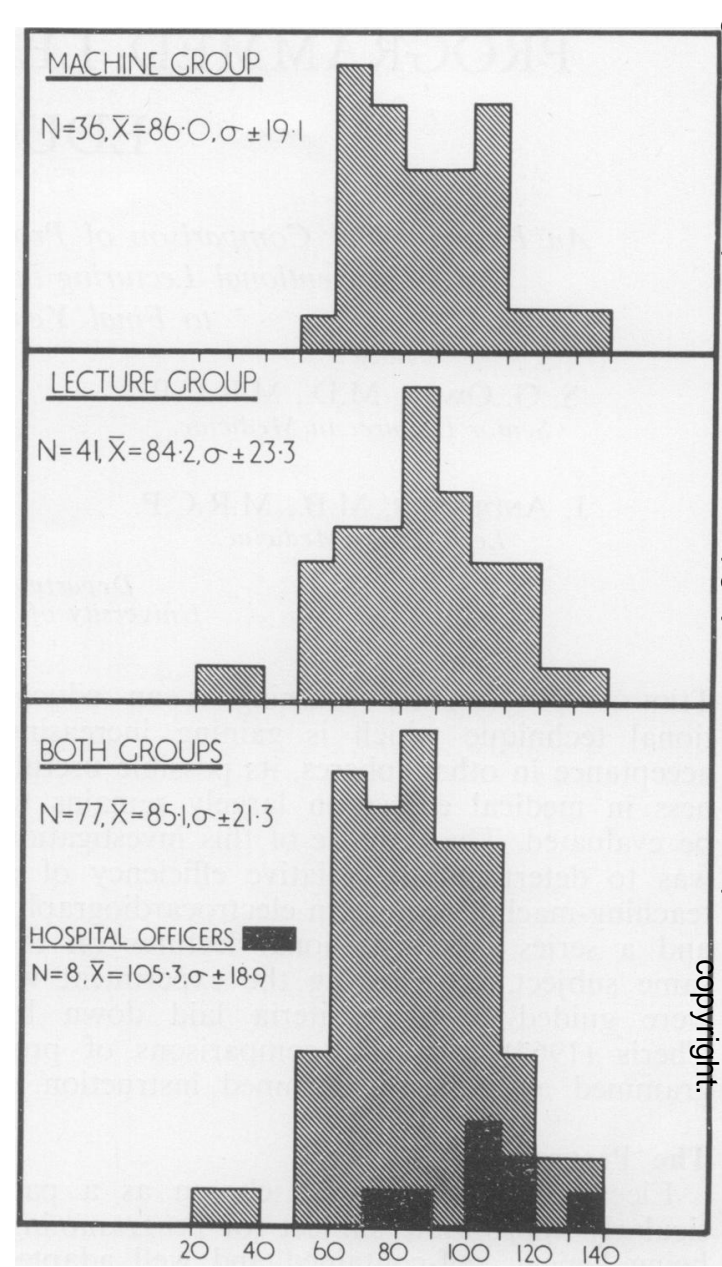

FIG. 1.-Distribution of scores in final ECG test.

revision immediately prior to the test. Since the amount of pre-test revision, unlike either total time or additional time spent during the course, proved to be significantly correlated with subsequent test scores $(\mathrm{P}<.05)$, this factor may be held to have favoured the lecture group. The reason for the difference is not clear, but it may be relevant that fewer machine-taught students stated that they had taken adequate notes throughout the course (64\% as compared with $88 \%$ in the lecture group, $\chi^{2} 6.12, \mathrm{P}<.025$ ).

\section{Teaching Method and Academic Ability}

Table 2 shows the mean test scores for the two teaching methods subdivided according to previous academic performance. Only in the lowest academic group were machine-taught superior to lecture-taught students (mean differ- 
TABLE 1

\begin{tabular}{|c|c|c|c|}
\hline \multicolumn{4}{|c|}{ Mean Time Spent in Learning } \\
\hline & $\begin{array}{c}\text { Machine } \\
\text { Taught }\end{array}$ & $\begin{array}{l}\text { Lecture } \\
\text { Taught }\end{array}$ & $\begin{array}{l}\text { Significance of } \\
\text { Difference }\end{array}$ \\
\hline $\begin{array}{l}\text { Total time spent including all } \\
\text { additional work (hours) } \\
\text { "Efficiency Index" of teaching }\end{array}$ & 17.05 & 16.64 & $F_{1,75}<1$, N.S. \\
\hline $\begin{array}{l}\text { method (mean values for test } \\
\text { score per hour spent) } \\
\text { Additional work during course }\end{array}$ & 5.04 & 5.06 & $F_{175}<1$, N.S. \\
\hline $\begin{array}{l}\text { (hours) } \\
\text { Pre-examination revision (hours) }\end{array}$ & $\begin{array}{l}1.21 \\
1.54\end{array}$ & $\begin{array}{l}2.48 \\
2.46\end{array}$ & $\begin{array}{l}F_{1,75}=6.53, P<.025 \\
F_{1,75}=4.30, P<.05\end{array}$ \\
\hline
\end{tabular}

TABLE 2

Teaching Method and Academic Ability

\begin{tabular}{ccccccc} 
Academic & \multicolumn{2}{c}{ Machine-Taught } & \multicolumn{2}{c}{ Lecture-Taught } & \multicolumn{2}{c}{ Totals } \\
Classification* & Mean Score & (Number) & Mean Score & (Number) & Mean Score & (Number) \\
1st $\left(\mathrm{c}^{* *} \geq 1\right)$ & 107.0 & $(7)$ & 117.8 & $(4)$ & 110.9 & $(11)$ \\
2nd $(1>\mathrm{c}>0)$ & 81.7 & $(10)$ & 86.2 & $(20)$ & 84.7 & $(30)$ \\
3rd $(0>\mathrm{c}>-1)$ & 77.0 & $(12)$ & 79.3 & $(12)$ & 78.1 & $(24)$ \\
4th $(-1 \geq \mathrm{c})$ & 86.4 & $(7)$ & 61.6 & $(5)$ & 76.1 & $(12)$ \\
TOTALS & 86.0 & $(36)$ & 84.2 & $(41)$ & 85.1 & $(77)$
\end{tabular}

* Academic classification based on average performance in two preceding professional examinations.

** c-normal deviate (e.g. average score of those in 1st group exceeded average for whole year by 1 standard deviation or more).

TABLE 3

Teaching Method and Sex

Mean Scores after Adjustment for Covariance with Previous Academic Performance Machine-Taught Lecture-Taught Totals

\begin{tabular}{lcccccc} 
& \multicolumn{2}{c}{ Machine-Taught } & \multicolumn{2}{c}{ Lecture-Taught } & \multicolumn{2}{c}{ Totals } \\
MEN & Mean Score & (Number) & Mean Score & (Number) & Mean Score & (Number) \\
WOMEN & 88.7 & $(24)$ & 81.1 & $(33)$ & 84.3 & $(57)$ \\
& 80.5 & $(12)$ & 96.9 & $(8)$ & 87.1 & $(20)$
\end{tabular}

TABLE 4

Teaching Method and Overseas Students

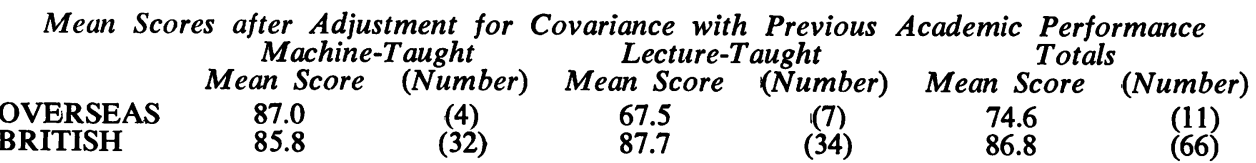

ence $=24.8, \mathrm{t}=1.86, \mathrm{P}<.10$ ). While this result is based on small numbers and dbes not quite attain the conventional level of statistical significance, it suggests that academically weaker students may learn electrocardiography more effectively by means of a teaching machine than from listening to lectures. Though the three higher academic groups show an increasing difference in favour of the lecture method, the figures afford no evidence that this is due to other than random variation (mean difference in top group $=10.8, \mathrm{t}=1.06, \mathrm{P}<.40$ ).

\section{Teaching Method and Sex}

Although there was no significant overall difference between the mean test scores in the two sexes, analysis of variance revealed a highly significant interaction between sex and teaching method which suggested that men were more effectively taught by teaching machines whereas women learned better from lectures. Similarly, machine-taught men were probably superior to machine-taught women $(\mathrm{P}<.10)$ but lecturetaught women were superior to lecture-taught men $(\mathrm{P}<.02)$. This apparent sex difference in teaching method effectiveness was due at least in part to initial differences in academic ability among the four sub-groups. However, even after elimination of the initial bias by analysis of covariance (Table 3), there still appeared to be a significant interaction between sex and teaching method $\left(\mathrm{F}_{1,72}=6.06, \mathrm{P}<.025\right)$. 


\section{TABLE 5}

Students' Reactions to Programmed Instruction

\section{Question}

Do you think this method of learning is more or less effective than listening to lectures?

Did you find it easier or harder to concentrate on the machine than you do on lectures?

Do you think this method of learning is more or less effective than reading the conventional textbook?

Did you find it easier or harder to concentrate on the machine than you do on textbooks?

\begin{tabular}{lr}
\multicolumn{1}{c}{ Answer } & $\%$ \\
More & 83 \\
Less & 0 \\
About the same & 11 \\
Not sure & 6 \\
Easier & 69 \\
Harder & 17 \\
About the same & 14 \\
Not sure & 0 \\
More & 83 \\
Less & 3 \\
About the same & 11 \\
Not sure & 3 \\
Easier & 75 \\
Harder & 6 \\
About the same & 19 \\
Not sure & 0
\end{tabular}

We believe that this rather surprising conclusion should be treated with reservation pending the results of further similar studies. One factor which may have in some measure contributed to the effect was the necessity for assigning six female students who were engaged in their resident midwifery appointment arbitrarily to the machine group, since they were unable to attend lectures. In relation to their known academic ability, their test performance was lower than that of the other 71 students. That this should be so is not difficult to understand, since conditions for studying during their residence in the maternity hospital were worse than those for other students.

\section{Teaching Method and Overseas Students}

English was not the native tongue of eleven of the seventy-seven students who took part in this experiment. Although they formed a small minority, it seemed important to determine the relative effectiveness of the two teaching methods in this special group. As before, the highly significant regression of test scores on previous academic performance was utilized by means of covariance analysis to minimise the effect of sampling fluctuations in academic ability.

Table 4 shows that, despite covariance adjustment for their poorer previous academic performance, the overall test scores of the overseas group were lower than those of the British students $(\mathrm{P}<.05)$. We feel that this is unlikely to represent any special difficulty in electrocardiography for the overseas students; more probably professional examiners, consciously or subconsciously, tend to make allowances for such handicaps as language difficulty, whereas the electrocardiography test, being wholly objective, could not be so influenced.

It is, however, of great interest that while the performance of overseas students in the lecture group was much poorer than that of their British colleagues $(\mathrm{P}<.01)$, in the machine group they did at least as well. Though the numbers are small, the data suggest that overo seas students are at a disadvantage when taught? by conventional lectures and that this can be overcome by programmed learning. Their greater fluency with the written than the spoken word and the advantages of self-pacing may be responsible for these results.

\section{Students' Reactions}

Table 5 summarises the opinions of the 36 students in the machine group about this method of learning.

\section{Summary}

Programméd instruction in electrocardiography presented by a teaching machine produced results just as good as very carefully prepared lectures. For academically poorer students and for those whose native tongue was other than English, the programme was probably the more effective teaching method. In this experiment women appeared to learn better from lectures and men from the programme, but further study is required to confirm the generality of this result. The students reacted favourably to programmed instruction and to teaching machines and expressed their preference for these over conventional methods of learning. 
This work was supported by a grant from the Leverhulme Trust through the Association for the Study of Medical Education. The authors also acknowledge the advice of Dr. J. L. Gibbons, Senior Lecturer in Psychological Medicine, and Mr. C. J. Duncan, Director of the Department of Photography, University of Newcastle-upon-Tyne, and the invaluable assistance of Mr. and Mrs. R. T. Johnson.

\section{REFERENCES}

Cheris, B. H. (1964): On Comparing Programming and Other Teaching Methods, J. med. Educ., 39, 304.

Owen, S. G., Hall, R., and Waller, I. B. (1964): Use of a Teaching Machine in Medical Education; Preliminary Experience with a Programme in Electrocardiography, Postgrad. med. J., 40, 59.

\section{DISCUSSION}

Chairman: Sir George Allen; Participants: B. Lennox (Glasgow), R. Hall (Newcastle), A. A. G. Lewis (London), R. Goodman (Brighton), M. EAST (Sandwich).

LENNOX (Glasgow). First of all, I am sure medical students are extremely bad people to try out new techniques of teaching on. They are highly skilled technologists (the good ones anyhow) in the art of learning, in extracting information, even from bad teachers and bad techniques of teaching. There have been previous investigations with results rather similar to this one. I know one on teaching pharmacology by various methods at London University, which again showed that if you assess the method really fairly it didn't matter very much how you taught students - you tended to get the same examination results in the end. Enthusiasm for new methods is a great thing, and the more new methods are introduced into teaching and the more the students are encouraged to take an interest in them the better, provided we realise that people at the latter end of a medical course are bad subjects for assessment of technical changes. The other matter is derived from our own experience in Glasgow on the testing of objective papers. You mention differences betwcen British and Overseas students. We came across a similar difference in their reaction to objective papers, but found one very important complicating element in this was the difference of age. Overseas students are nearly all at least three years older than corresponding British students, and one should be exceedingly careful to eliminate this factor before drawing any conclusions from their being overseas students. Language diffculties seem to be among the least of the difficulties of overseas students, incidentally

HALL (Newcastle). I think that that is very helpful, Dr. Lennox. We certainly had not considered this increased age of the overseas student. This is something we can analyse and see if we can get anything more out of it. I must say I agree with you that the teaching method probably doesn't matter very much for the better student, but at least new teaching methods stimulate the enthusiasm of the teacher, and I think this is probably one definite advantage they have got.

LEWIS (London). I would like to congratulate Dr. Hall on a brilliant paper and a brilliant presentation. I would also like to congratulate him on his apparent sex-appeal. May I ask some of the general practitioners here whether they think this might not be a good method for revision of essential factual material for general practitioners, perhaps in community centres, health centres or small hospitals? I believe that one of the troubles in reaching general practitioners in postgraduate education is that they so dislike showing their ignorance, or their supposed ignorance, in lectures and demonstrations at medical centres given by specialists. We always find them most reluctant to come forward and ask questions; when they do they do so often with an apparent diffidence, an attempt to disguise perhaps, this supposed area of ignorance which may not really exist at all. If you could have some of these teaching machines and some good programmes in centres where general practitioners perhaps could go on their own in a small booth and really work the thing out for themselves, I believe you would have made a real advance in getting it over to them. I would like to get other people's comments.

GOODMAN. One of the significant findings of most researchers in this field is that when you attempte (and whether this is justified or not, I don't know, I suspect it is probably not), to compare learning results from the use of teaching machines as opposed to programme texts, there is no significant difference, at the level of programming techniques that we have today. It might therefore be just as well not to try to provide medical practitioners with teaching machines in the field but to send them out programme texts which they could, in the relative comfort of their own homes, work through, rather than dragging them out to centres where the machines are. This is the kind of thing which I believe has at least been done on one occasion by Messrs. Pfizer in the States using a programme on Allergy and Hypersensitivity.

A QUESTIONER. Dr. Lewis has mentioned booths for learning and I would suggest that they could be put on the pier at Brighton instead of "What the Butler Saw". With this kind of programmed learning, is there any danger of turning a man into a goon instead of into a thinking animal and the other question I would like to ask is, "How do we store information in our brain because $I$ know my own brain is an absolute miscellaneous jumble of disconnected facts. How much can we store in any one year and in a lifetime?"

GOODMAN. I would like to leave the second part of the question until a bit later. The suggestion that these new techniques may turn people into goons or other non-human objects can I think be safeguarded against by the way in which we use these techniques in the general context. This is the point which I was trying to make in my own paper, that we don't rely on these techniques by themselves. We use them where we think they are advisable and where we 
think they are efficient to do partial jobs and jobs which in the context either the human teacher can't do because he hasn't the time, he can't attend to a large number of people individually or where it is possible that the system will do it rather more efficiently than he can. This is why I emphasise the fact that the nucleus of any learning situation must inevitably be social. This is a safeguard against the production of goons. On the second point I think the answer is, nobody knows! But I would draw your attention to some very interesting work which has been done by Feigenbaum at the Rand Corporation in America. And though of course the conclusions were by no means positive, they were suggestive only, it did seem that if you use computer simulations to attempt to answer this kind of question, or at least to explore your way through the implications of such a question, you can get a fair way forward.

HALL. Could I just add one point to Dr. Lewis's comment. We indeed have found that a lot of general practitioners have come up to us and asked if they could use the teaching programme on electrocardiography, so a number of them are really quite interested in this. The other thing of course is that using a teaching programme doesn't convert you into being a goon, it prevents you being one, because with ordinary teaching methods all one has to do is to sit back and you present them with the material-whereas, with the teaching programme, the essence is that you participate in it so you get much more thought involved in learning than you normally do. This is a very good trend.

EAST (Pfizer). First I would also like to congratulate Dr. Hall on his excellent paper. There is one query I would like to make-this is something which was brought up by Mr. Goodman-that you are testing the machine against lectures which presented identical material as the machine was, i.e. the programmed stuff was being given by the lecturers. Would it not have been a much fairer test of the type of method, to have asked the lecturers who had better reputations for lecturing in the Unit, to prepare their own lectures to cover the same ground, in other words, the same way as they would have done had there been no machines and then really see what the answer is then.

HALL. Well, there are a whole host of ways we could have done this. We thought the most important thing was to make sure that there were absolutely identical contents in the two courses and then the only thing tested was the method of teaching. We thought that if we introduced any other variables into this it might be more difficult. Really the way you design this experiment you can get any result you want and we wanted to bias it as much in favour of the lecture group as possible because any new teaching method should be able to stand on its own feet and be better than the best that you can produce by a conventional method. We thought that this was probably the fairest thing in the long run but $I$ agree this would have been an alternative way of doing it. We could only do it once because the amount of work involved was pretty phenomenal and we used a whole year of medical students to do this, so we have got to wait for another year to go on

GOODMAN. I think I would just like to come back on this. I think a very serious objection has been made to methodology of testing. The question really is: if you do any comparative tests of this kind, whether you are comparing samples from the same universe; comparison tests of this kind, though they are very valuable from an indicative point of view, are not by any means adequate in their design to answer the kind of question we are trying to ask. You are in fact probably sampling from two different universes of which there is only one examplar. Probably the most effective way of validating and testing your programmes is by giving the students a test before entry and a test after entry: to see whether effective learning has taken place as a result solely of their working through the programme. But this again raises another problem which has been illustrated by some experiments done by the Admiralty: the actual interaction of tutor with programme sequence. The Admiralty did three experiments. Very briefly, they did a comparison test on the lines that we have been discussing and on the whole there were favourable results so far as the teaching machine presentation was concerned. They then repeated this and the results were disastrous from the point of view of the teaching machine. What happened was, that instead of actively using the human tutor at all they demoted him to the position of supervisor to prevent the machines being thrown out of the window by irate ratings. The result was that not only were the examinaz tion results extremely bad, but it is said, the unfortunate instructor very nearly had a nervous breakdowne They then had the courage to proceed to a third experiment in which they now used the human teacher in a very much more active tutorial function. He went around, he discussed with the students, while they were working on the machines, their problems, he got to know them individually and the results were extremely exciting.. The performance from that group, which was a very average one, in the conventional tests was splendid and not only did the human instructor not have a breakdown, but what is more he expressed the view that this was a very exhilarating experience. He had got to know his students individually for the first time and was able to do this, conscious of the fact that $99 \%$ of them would be continuing to work and learn, while he was dealing with one particular individual. Finally, if I could tell you a story which is relevant to Dr. Hall's experience: In the early days of programming, a comparison test of the kind that we have been discussing took place and to everybody's horror, at least to the horror of the teaching machine addicts, the human instructor did very very significantly better than the machine. This really was a scandal. But in point of fact the reason was that the lecturer had himself written the programme and had gained so much as a result, that he had done better than the actual machine. 